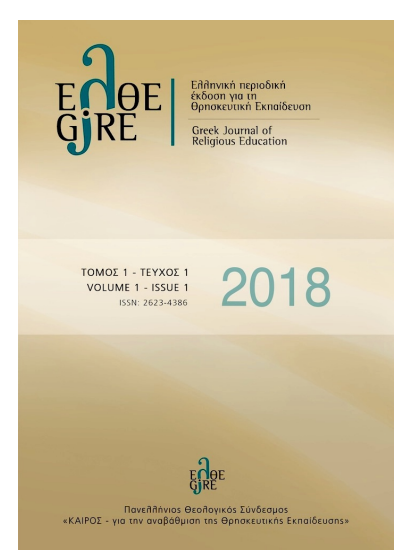

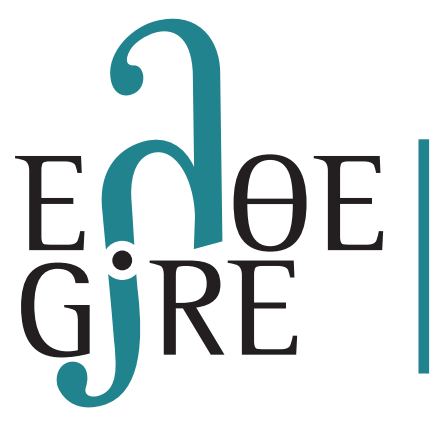

Eลกททıкń пยрıобıкń

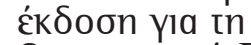

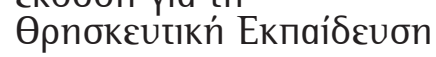

Greek Journal of

Religious Education

ISSN: 2623-4386.

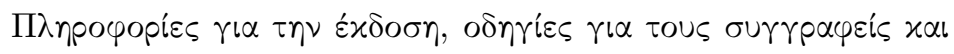

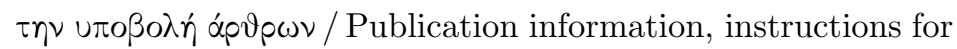
authors and subscription information: http://www.gjre.gr

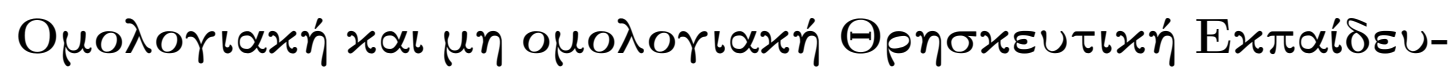

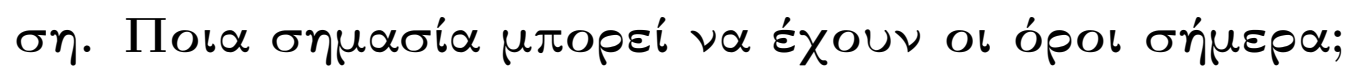

Confessional and non-confessional RE. What would be the meaning of the terms today?

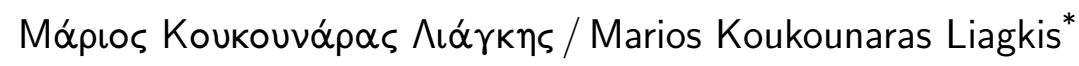

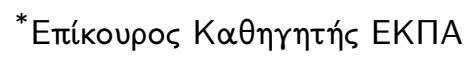

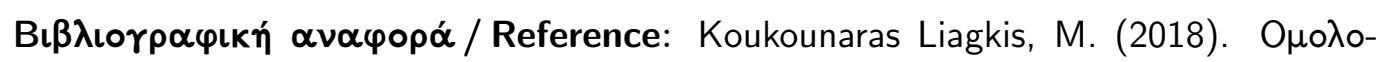

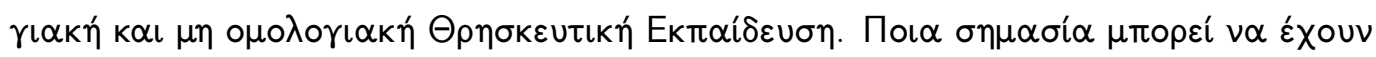
ol ópol $\sigma \eta \dot{\mu} \mu \varepsilon \rho \alpha$; / Confessional and non-confessional RE. What would be the meaning of

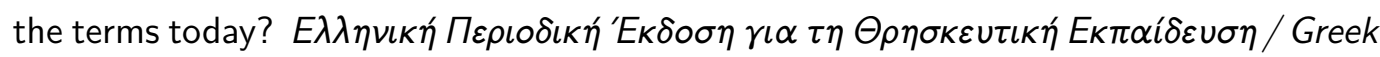
Journal of Religious Education, 1(1), 1-8, DOI: 10.30457/031020181

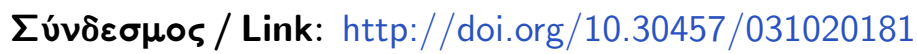

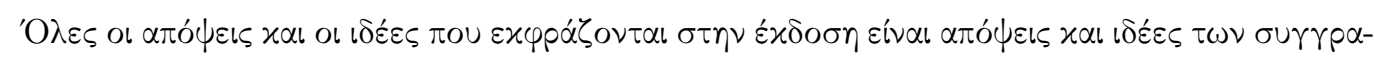

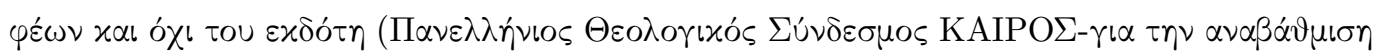

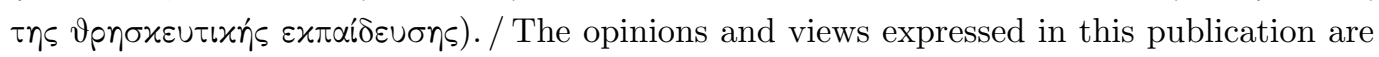
the opinions and views of the authors and not of the publisher (KAIROS - Greek Theological Association for the improvement of the Religious Education).

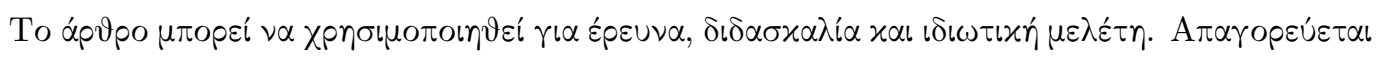

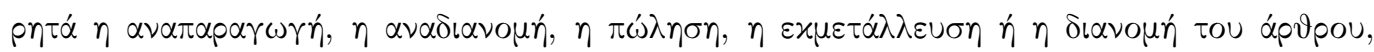

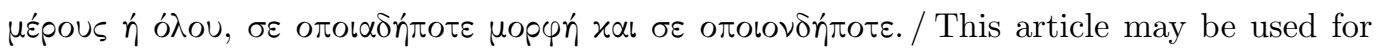
research, teaching, and private study purposes. Any substantial or systematic reproduction, redistribution, reselling, licensing or distribution in any form to anyone is forbidden.

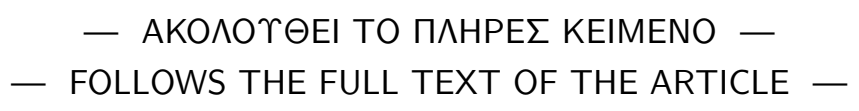




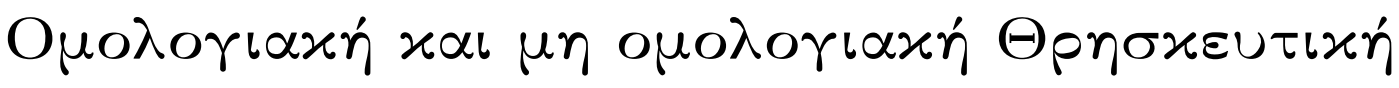

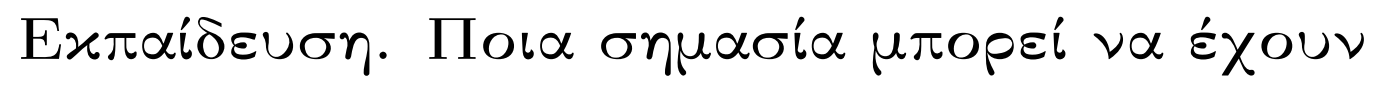

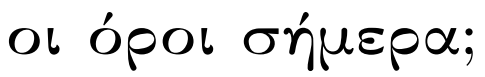

\section{Confessional and non-confessional RE. What would be the meaning of the terms today?}

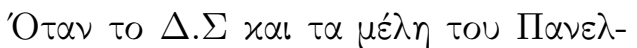

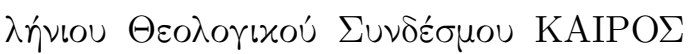

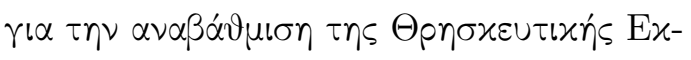
$\pi \alpha i \delta \varepsilon v \sigma \eta s$ a

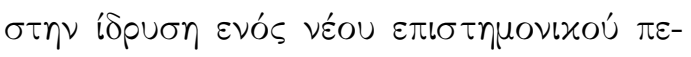

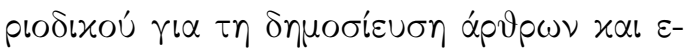

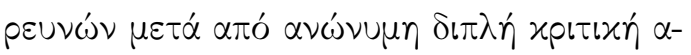

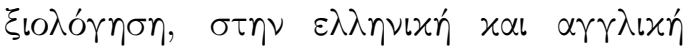

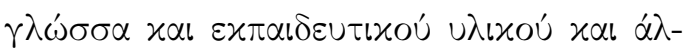

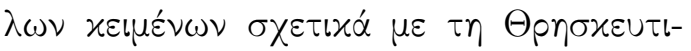

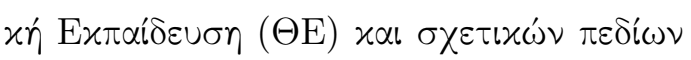

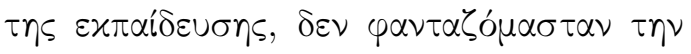

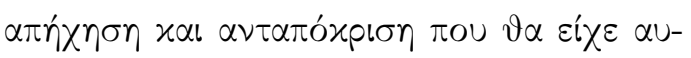

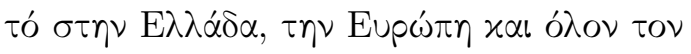
xóøuo.

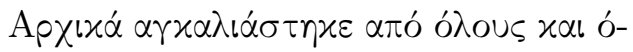

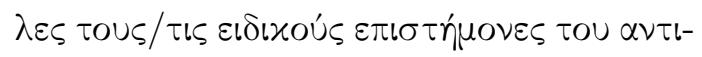

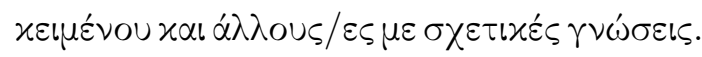

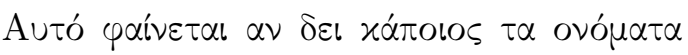

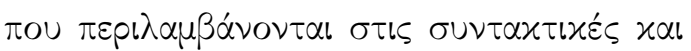

When the Board and the members of 'KAIROS - the Greek Theological Association for the improvement of Religious Education' decided to establish a new peerreview scientific journal for the publication of articles in Greek and English, as well as educational material and other texts on Religious Education and related fields of education, we could not have imagined the resonance and response it would have in Greece, Europe and indeed, globally.

It was initially embraced by not only expert scientists in the field but also others with relevant experience. A glance at the list of names in the editorial and scientific committees of the journal, both 


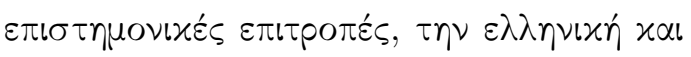

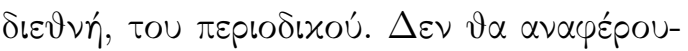

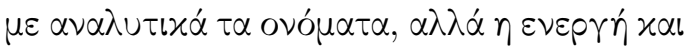

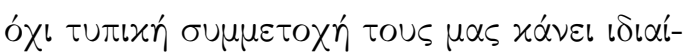

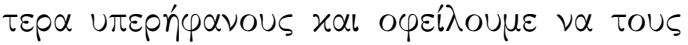

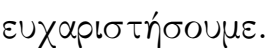

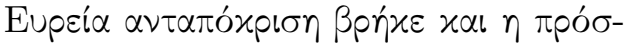

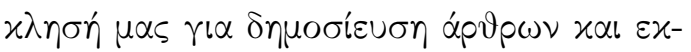

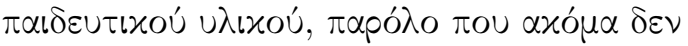

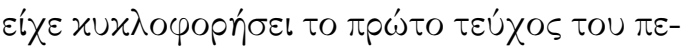

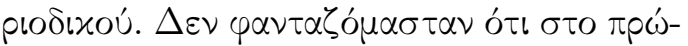

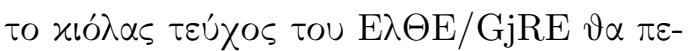

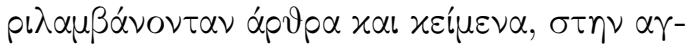

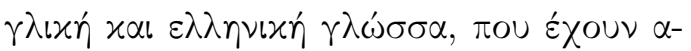

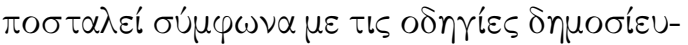

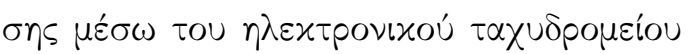

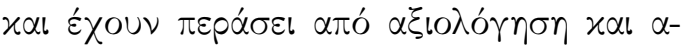
$\nu \omega ́ v \cup u \eta \eta$

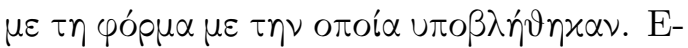

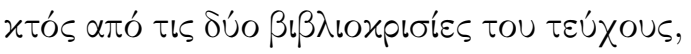

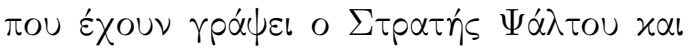

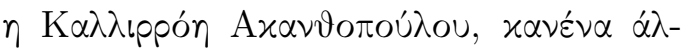

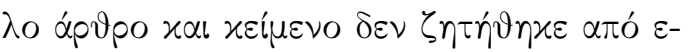

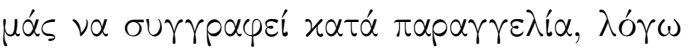

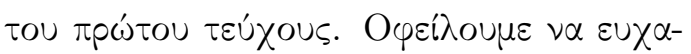

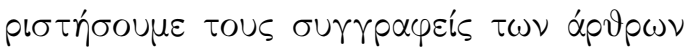

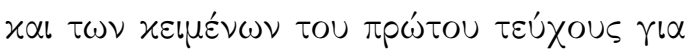

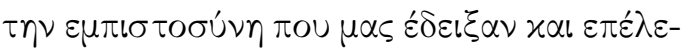

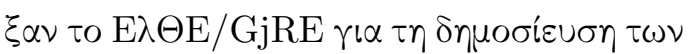
ápvpouv tous.

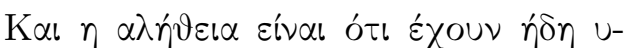

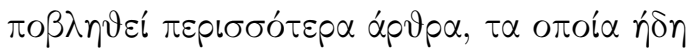

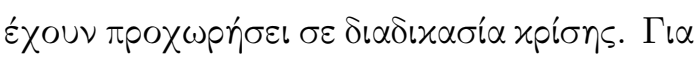

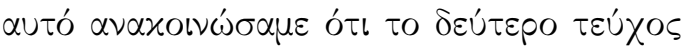

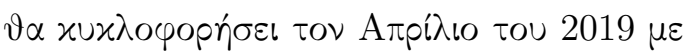

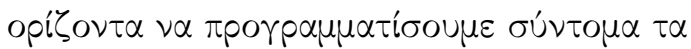

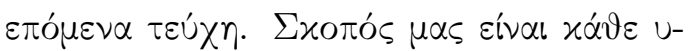

Greek and International, makes this evident. While not making reference to the names in detail, their active and keen participation, however, makes us particularly proud and we owe them our thanks.

Our invitation to publish articles and educational material met with an enthusiastic response, despite the first issue not having been released yet. We did not expect that the first issue of $\mathrm{E} \lambda \Theta \mathrm{E} / \mathrm{GjRE}$ would include a wealth of articles and texts in both Greek and English, which were sent according to the publication instructions via e-mail and have been evaluated and peer-reviewed, according to required template for submission.

Apart from the two book reviews in this first issue, written by Stratis Psaltou and Kallirroi Akanthopoulos, no other article and text was written on demand, this being the first issue. We need to thank the authors of the articles and the texts of the first issue for the trust they have put in us by choosing $E \lambda \Theta E / G j R E$ for the publication of their articles.

The truth is that more articles have already been submitted and they have already been through a peer-review process. That is why we have announced the release of the second issue in April 2019, the aim being to release the publication dates of the next issues as promptly as possible. Our aim is to peer-review any submitted article as soon as possible and to publish it in the shortest possible time. This is why the call for submission of peer-review 


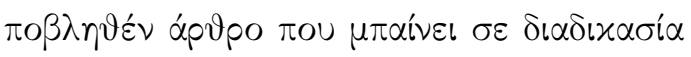

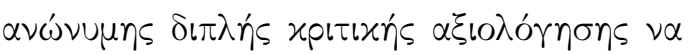

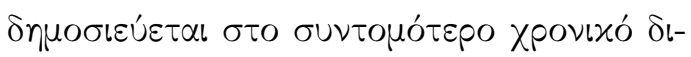

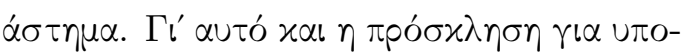

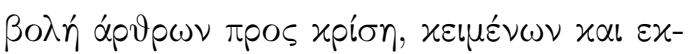

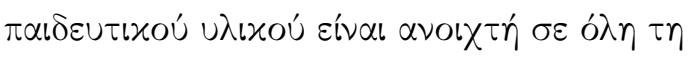

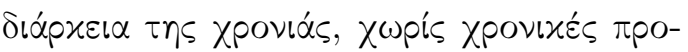

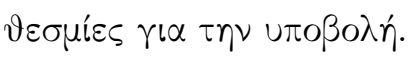

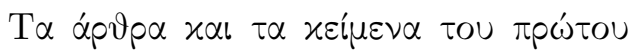

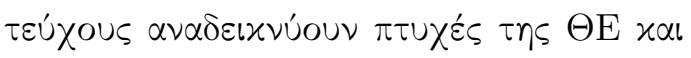

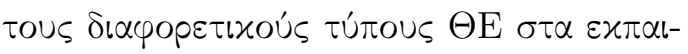

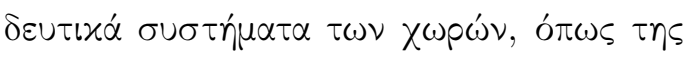

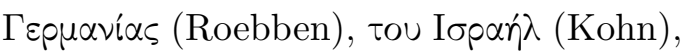

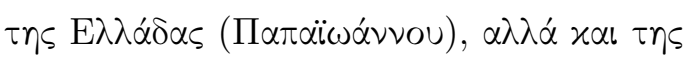

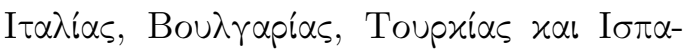

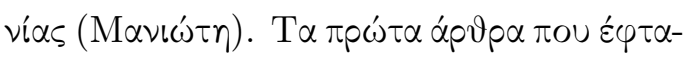

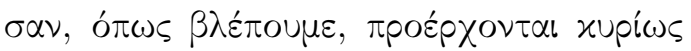

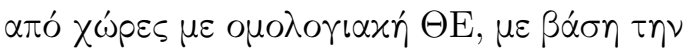

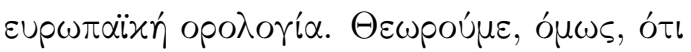

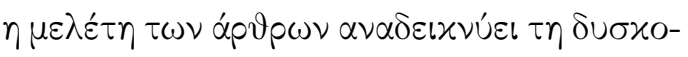

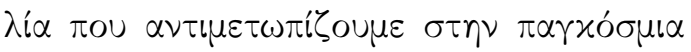

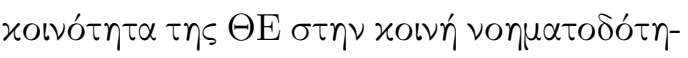

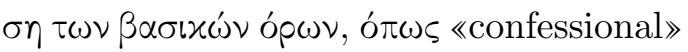

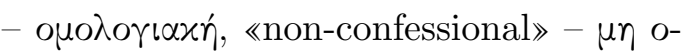

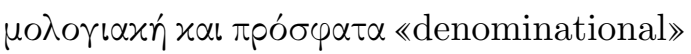

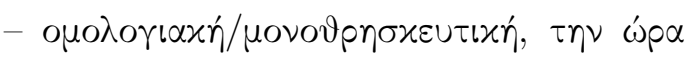

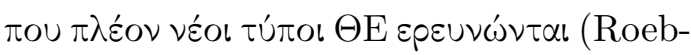

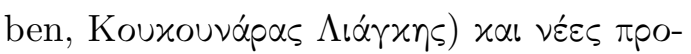

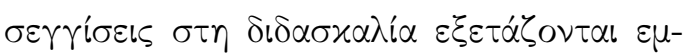

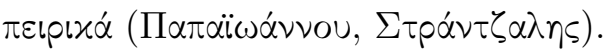

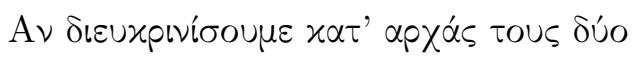

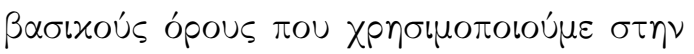

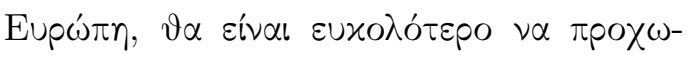

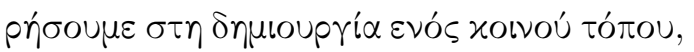

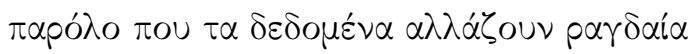

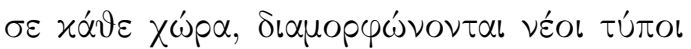

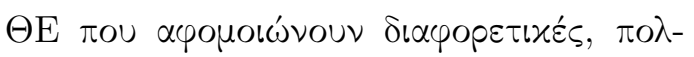

articles, texts and educational material is open throughout the year, with no time limits for submission.

The articles and texts of the first issue highlight aspects of RE and different $\mathrm{RE}$ types in educational systems in countries such as Germany (Roebben), Israel (Kohn), Greece (Papaioannou), but also Italy, Bulgaria, Turkey and Spain (Manioti). The first articles that arrived, as can be seen, come mainly from countries with a confessional RE, based on European terminology. We believe, nevertheless, that the study of the articles highlights the difficulty we face in the global community of RE in the common understanding of the basic terms, such as "confessional", "non-confessional", and recently "denominational", while new types of RE are being researched (Roebben, Koukounaras Liagkis) and new approaches to teaching are examined empirically (Papaianoannou, Stratzalis).

By initially clarifying the two basic terms we use in Europe, it will be easier to move to the development of a common ground, although the data is changing rapidly in each country; new types of RE are formed assuming different, often pedagogical, theological and philosophical approaches (eg in Denmark, Sweden, Latvia, etc.) or even the position 


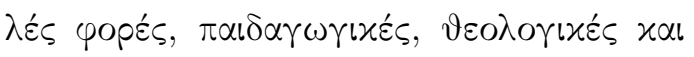

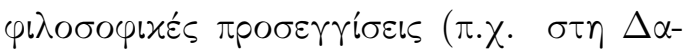

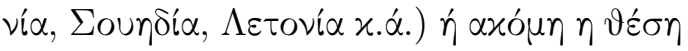

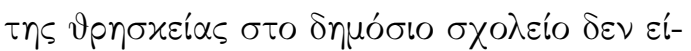

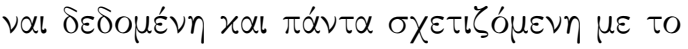

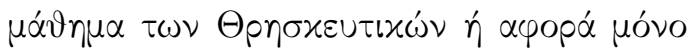

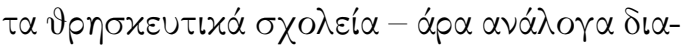

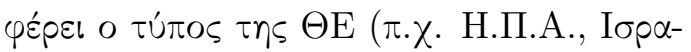

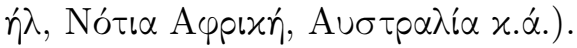

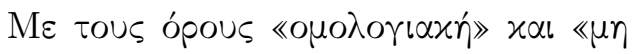

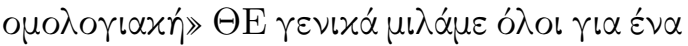

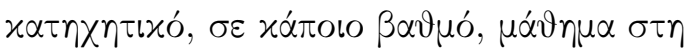

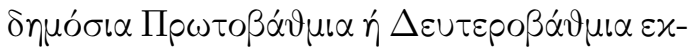

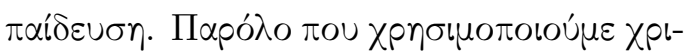

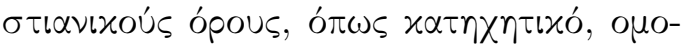

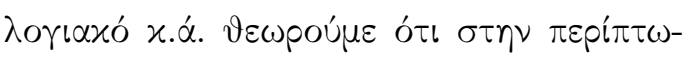

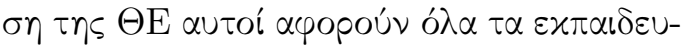

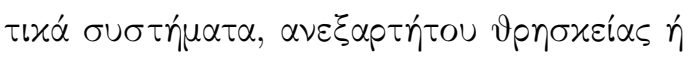

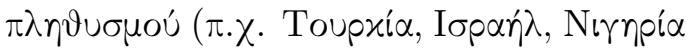

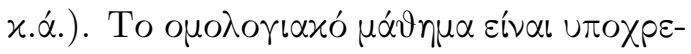

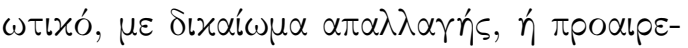

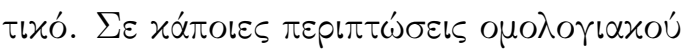

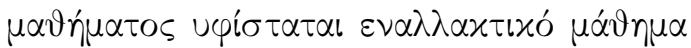

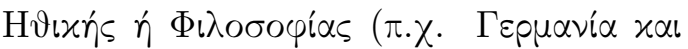

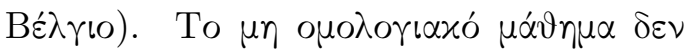

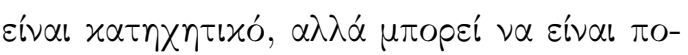

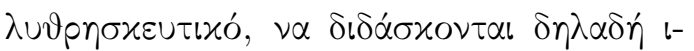

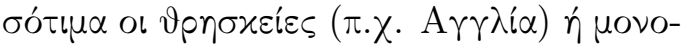

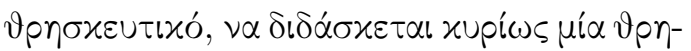

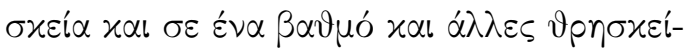

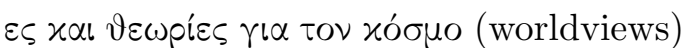

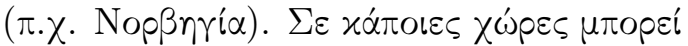

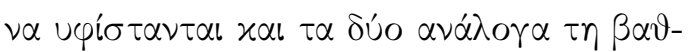

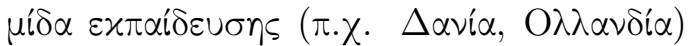

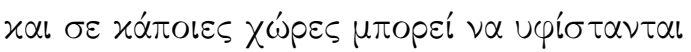

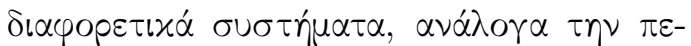

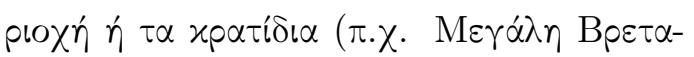

of religion in state schools is not a given and is always related to RE or only concerns religious schools (such as those in the US, Israel, South Africa, Australia, etc.).

With the term "confessional" and "non-confessional" RE, we generally talk about a catechetical, to a certain extent, subject in Primary or Secondary Education. Although we use terms derived from Christianity, such as catechetical, confessional, etc. we think that in the case of $\mathrm{RE}$, they concern all educational systems, regardless of the religion of the state or the population (e.g. Turkey, Israel, Nigeria, etc.). Confessional RE is compulsory, with a right of exemption, or optional. In some cases, an alternative course of Ethics or Philosophy exists (e.g. Germany and Belgium). Non-confessional RE is not catechetical, but it may be multi-religious, namely religions being taught equally (e.g. England), or mono-religious, one religion and, to some extent, other religions and worldviews being taught, (e.g. Norway).

In some countries there may be both $\mathrm{RE}$, confessional and non-confessional, depending on the levels of the education Primary and Secondary (e.g. Denmark, the Netherlands), and in some countries there may be different systems and types, depending on the region or the different states (e.g. UK, Germany etc.). In addi- 


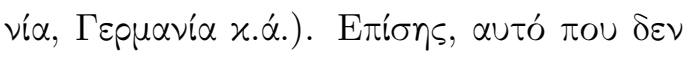

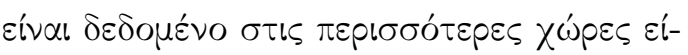

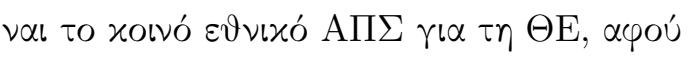

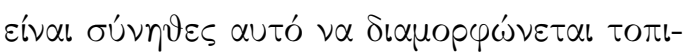

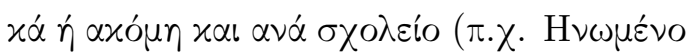
$\mathrm{B} \alpha \sigma i \lambda \varepsilon\left\llcorner O, \mathrm{O} \lambda \lambda \alpha \nu \delta \delta^{\prime} \alpha\right)$.

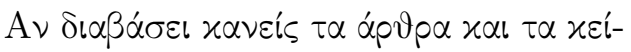

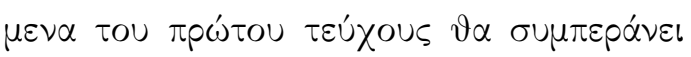

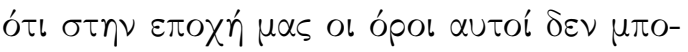

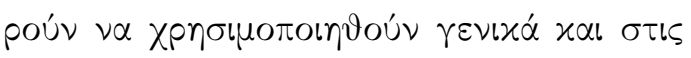

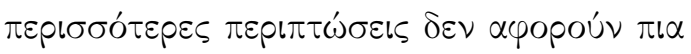

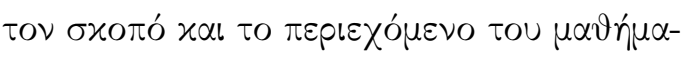

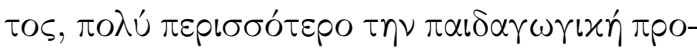

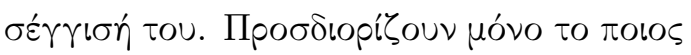

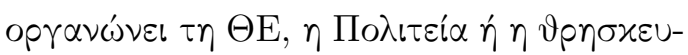

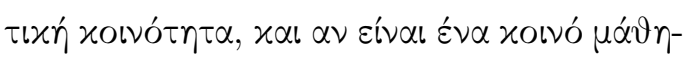

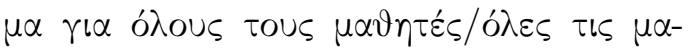

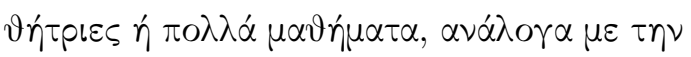

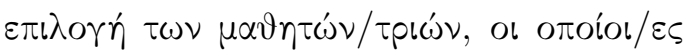

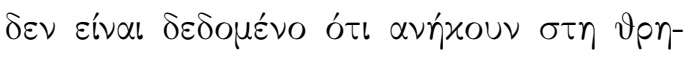

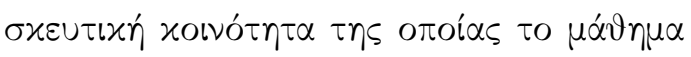

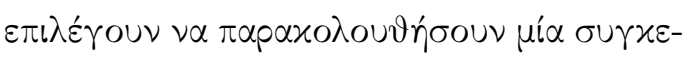

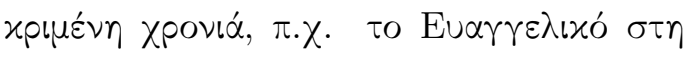

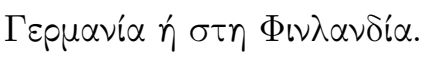

O ópos «denominational» $\vartheta \varepsilon \omega p o u ́ \mu \varepsilon$ ó $\tau ا$

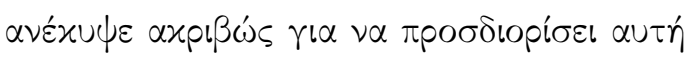

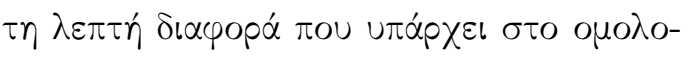

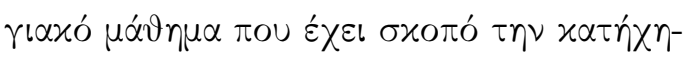

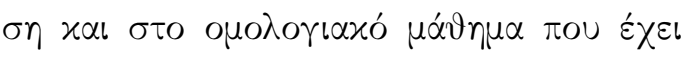

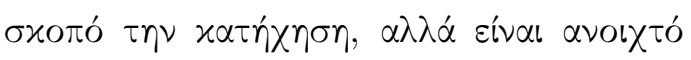

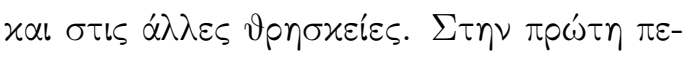

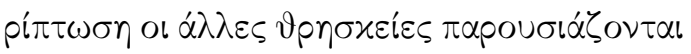

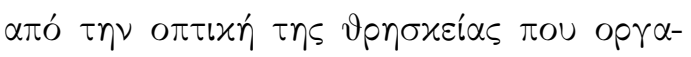

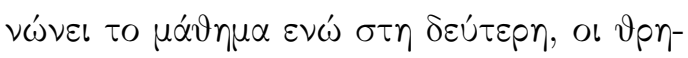

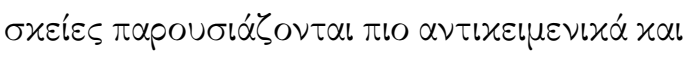

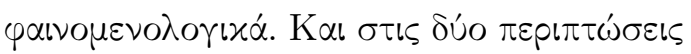

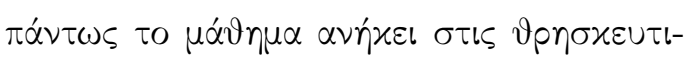

tion, what is not given in most countries is the common national Curriculum for RE, since it is usual for it to be formed locally or even by the school (e.g. the UK, The Netherlands).

If one reads the articles and texts of the first issue one might come to the conclusion that in our times these terms cannot be used generally and, in most cases, they no longer concern the purpose and content of RE, let alone its pedagogical approach. They identify only those who organize RE - the State or the religious community and, whether it is one subject for all students or many different courses; depending on the choice of students where it is not a given that they belong to the religious community pertaining to the $\mathrm{RE}$ lesson they chose to attend that year, e.g. the Evangelical in Germany or Finland.

The term "denominational" is thought to have arisen precisely to identify this subtle difference between the confessional $\mathrm{RE}$ that has as its aim catechism and the confessional RE that has as its aim not only catechism but is also open to other religions. In the first case, other religions are presented from the perspective of the religion that organizes the RE lesson, while in the second, religions are presented more objectively and phenomenologically. In both cases, however, RE belongs to the religious communities. 


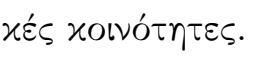

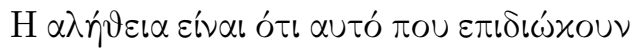

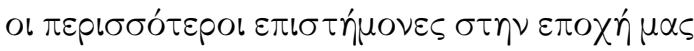

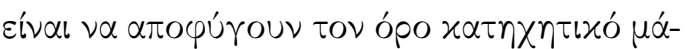

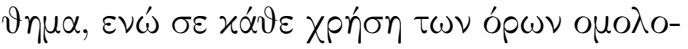

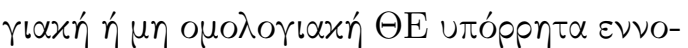

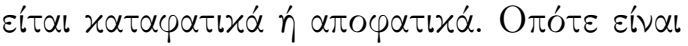

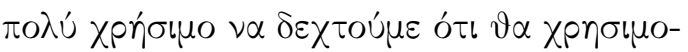

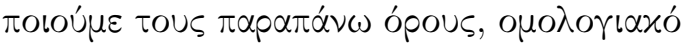

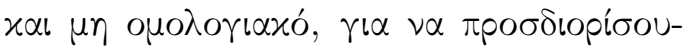

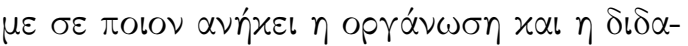

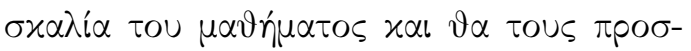

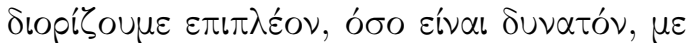

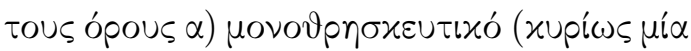

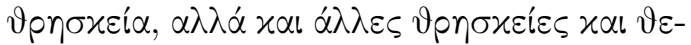

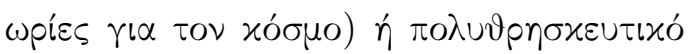

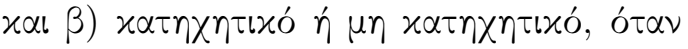

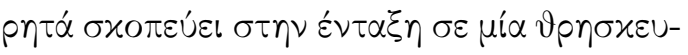

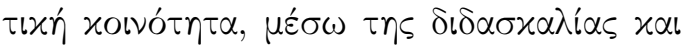

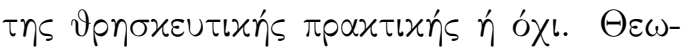
роú

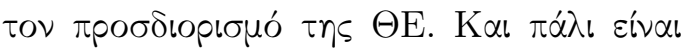

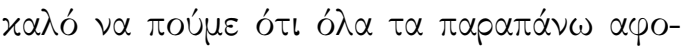

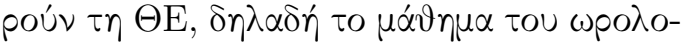

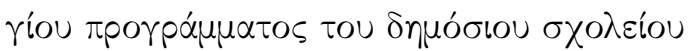

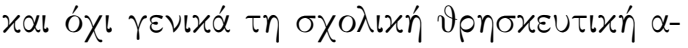

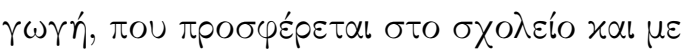

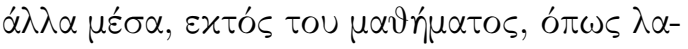

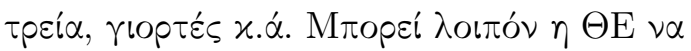

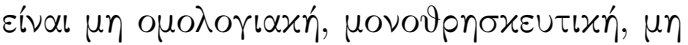

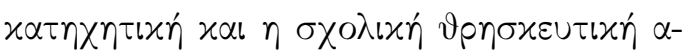

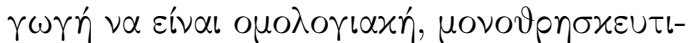
$x \dot{\eta} x \alpha \iota x \alpha \tau \eta \chi \eta \tau \iota x \dot{\eta}(\pi \cdot \chi . \sigma \tau \eta \nu \mathrm{E} \lambda \lambda \alpha \dot{\alpha} \alpha \alpha, \mu \varepsilon \tau \alpha \dot{\alpha}$ to 2016).

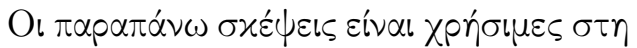

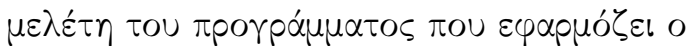
Bert Roebben $\sigma \tau \eta \Gamma \varepsilon p \mu \alpha v i \alpha, \sigma \varepsilon \mu i \alpha \chi \omega \dot{\omega} \rho \alpha$
The truth is that what most scientists seek in our time is to avoid the term catechetical RE, while any use of the term confessional or non-confessional RE, is implicitly thought of as affirmative or negative. So it is very useful to accept that we will use the terms confessional and nonconfessional to determine to whom the organization and teaching of the subject belongs, and we will further identify them as far as possible with the terms of a) monoreligious (especially one religion, but also other religions and worldviews) or multireligious and b) catechetical or noncatechetical when its express intention is to integrate someone into a religious community through teaching and religious practice or not.

We believe that this is a more honest and clear definition of RE. Again, it is worth noting that all the above concern RE, that is, the subject of the state school curriculum and not school religious education generally, which is offered at school through other means other than the lesson, such as worship, celebrations etc. That means that RE as a subject may be non-confessional, mono-religious and non-catechetical while school religious education may be confessional, monoreligious and catechetical (e.g. in the case of Greece, after 2016).

The above considerations are useful in studying the program implemented by Bert Roebben in Germany, a country with 


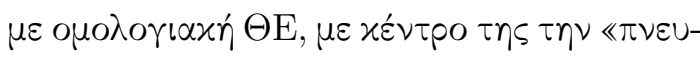

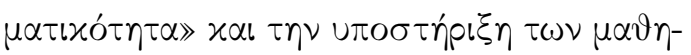

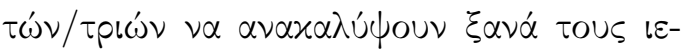

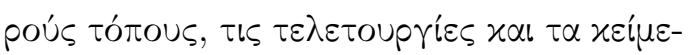

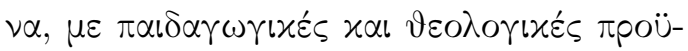

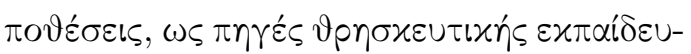

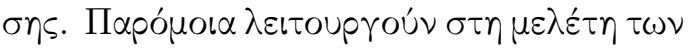

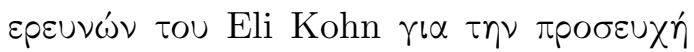

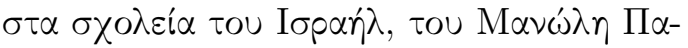

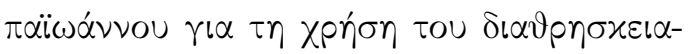

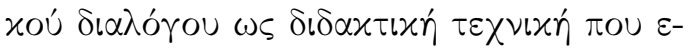

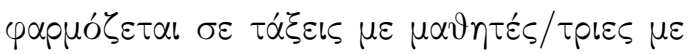

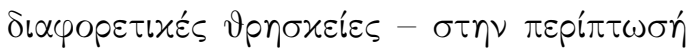

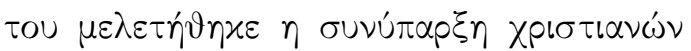

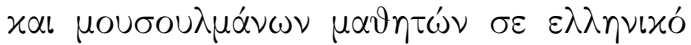

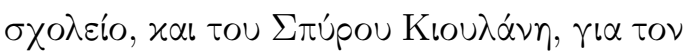

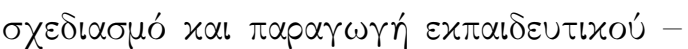

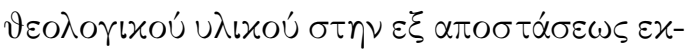

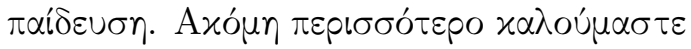

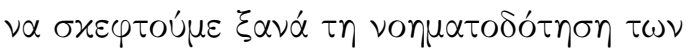

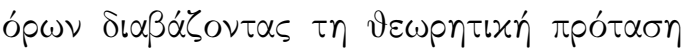

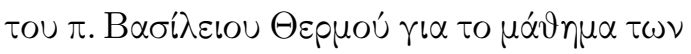

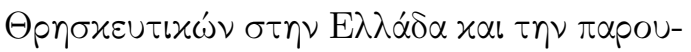

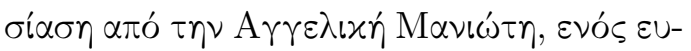

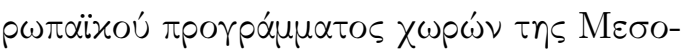

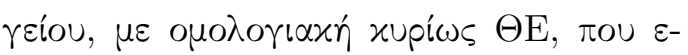

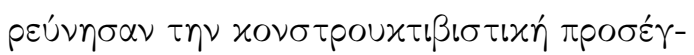

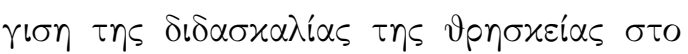
$\sigma \chi 0 \lambda \varepsilon i ́ 0$.

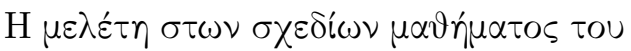

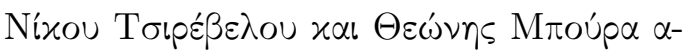

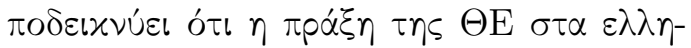

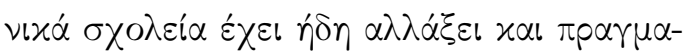

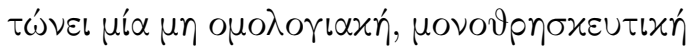

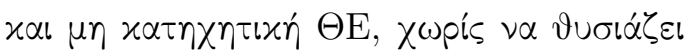

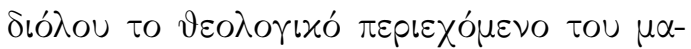

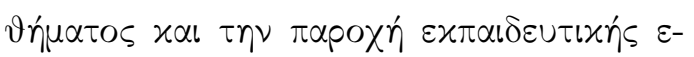

a confessional RE, centered on "spirituality" which supports students in rediscovering the holy places, rituals and texts, with pedagogical and theological preconditions, as sources of religious education. Similarly, there is the same function of the above considerations in the study of Eli Kohn's research on prayer in Israeli schools, Manolis Papaioannou's research on the use of interfaith dialogue as a teaching technique applied to classes with pupils with different religions - in his case, the study of the coexistence of Christian and Muslim students in a Greek school - , and another research by Spyros Kioulanis, on the design and production of educational and theological material for distance learning. Even more so, we are called upon to think again about our understanding of the terms by reading the theoretical suggestion of Rev.Vasilios Thermos for RE in Greece and the presentation by Angeliki Manioti, of a European program in the Mediterranean countries with a mainly confessional RE, who has explored the constructivist approach to teaching religion at school.

The study of the lesson plans by Nikos Tsirevelos and Theoni Boura demonstrates that the practice of RE in Greek schools has already changed and realizes a nonconfessional, mono-religious and noncatechetical RE without sacrificing the theological content of the subject and the educational experience for one vague for- 


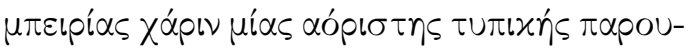

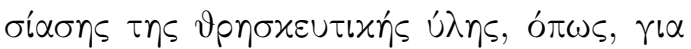

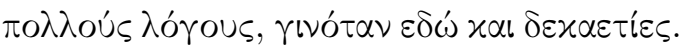

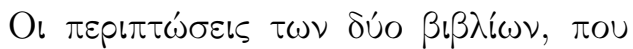

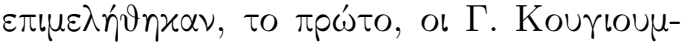

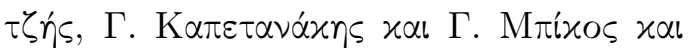

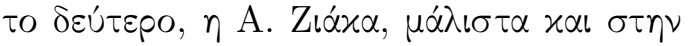

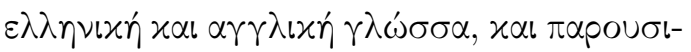

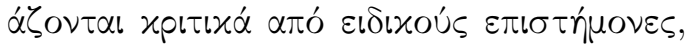

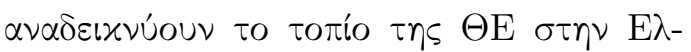

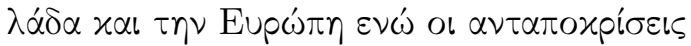

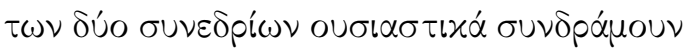

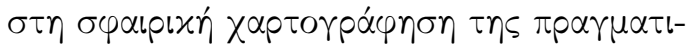

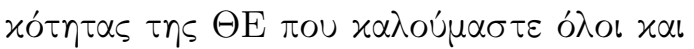

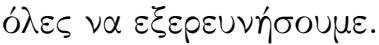

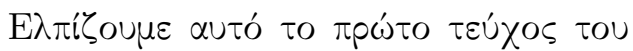

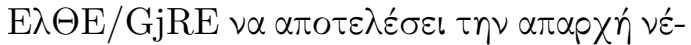

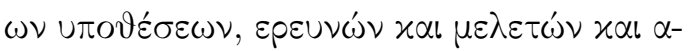

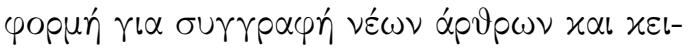

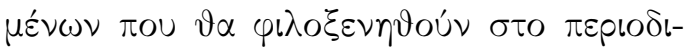

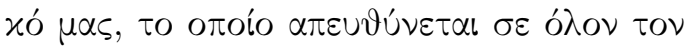

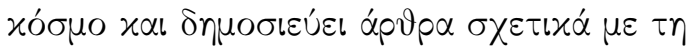

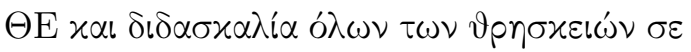

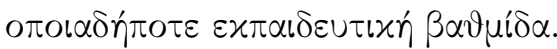

$K \alpha \lambda \dot{n} \mu \alpha \varsigma \alpha p \times \eta_{n} !$ mal presentation of religious matter, as has been the case for many reasons over the decades.

The cases of the two books, the first edited by G. Kougioumtzis, G. Kapetanakis and G. Bikos, and the second by A. Ziaka, in Greek and English, that have been presented critically by experts, highlight the landscape of RE in Greece and Europe, while the reports of the two conferences essentially contribute to the global mapping of the RE reality that we all have to explore.

We hope that this first issue of $\mathrm{E} \lambda \Theta \mathrm{E} / \mathrm{GjRE}$ will be the beginning of new hypotheses, researches and studies and the occasion for writing new articles and texts to be hosted in our journal, which is addressed to the whole world and publishes articles on RE and teaching of all religions at any and every educational level.

May it be a fruitful beginning!

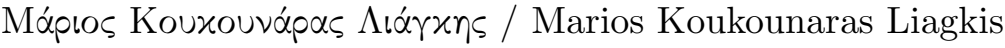

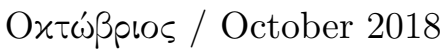

